\title{
The Contribution of Renewables to Society
}

\author{
Göran Berndes
}

\subsection{Introduction}

Stocks and flows of biomass are vital components of the biogeochemical system of the Earth. Biomass builds up the ecosystem, which contains the reservoir of genetic and species diversity and provides environmental services such as water purification, waste assimilation, soil fertility rehabilitation, water runoff regulation and flood control. Biomass is also crucial for human subsistence in other ways as it serves as food, and can be used for energy purposes and for the production of, e.g., sawn wood, paper, and various chemicals. Throughout history, human societies have ultimately depended on the management and harvest of biological (land and water) resources, and their inability to sustain their productivity have led to the end of their civilizations (Ponting, 1992).

Thus, human beings have always influenced their habitats, and still today the conversion of ecosystems to land for biomass production is perhaps the most evident alteration of the Earth. However, emissions to air and water also lead to substantial environmental impacts and a large portion of these emissions come (directly or indirectly) from other than land use activities. The industrialized society of today is unique historically in that access to biomass does not impose the ultimate limit: humans have learned to decouple industrial activities from biological productivity by exploiting fossil resources in the form of petroleum, coal and gas and this ability proved a powerful driver of societal development in the twentieth century. The role of biomass as a source

Renewables-Based Technology Edited by J. Dewulf and H. Van Langenhove (C) 2006 John Wiley \& Sons, Ltd 
of energy has steadily declined and the global energy system is today dominated by fossil fuel use. The petrochemical industry creates synthetic materials and chemicals that successfully compete with biobased products, and also the food sector has undergone dramatic changes: most of our food still comes from agriculture, but is today produced in an intensive manner that relies on fossil fuels and petroleum-based chemicals, where synthetic nitrogen fertilizers are among the crucial causes behind the past century's transformation of world food production (Smil, 2001).

In the twentieth century, the impacts of human society on nature escalated. At the beginning of the twenty-first century, human societies have put almost half of the world's land surface to their service, and have caused extensive land degradation and loss of biodiversity worldwide (Turner II et al., 1990, Oldeman et al., 1991, Groombridge and Jenkins, 2002). Human activities influence global biogeochemical cycles, bringing about environmental effects such as eutrophication, acidification, stratospheric ozone depletion and climate change (Figure 1.1). It is clear that the substitution of biomass with fossil resources (and the intensification of agriculture) have saved large areas from deforestation and conversion to agricultural land. But at the same time, much of the environmental impacts we see today is caused by the intensified land use and the use of petroleum, coal and fossil gas. For that reason, today there are attempts to reduce our dependence on fossil resources and return to relying more on biomass and other renewable resources for our subsistence. Addressing the concerns about climate change, land degradation and other environmental impacts, while providing food, energy and materials for a growing and wealthier global population, will be a formidable challenge.

This chapter will discuss the potential role of biomass as a renewable resource in a future global industrial society. Some analysts, such as Hoffert et al. (2002), dismiss biomass as an important future renewable resource, especially in the context of energy system transformation and climate stabilization. Others take the opposite view and propose biomass as one of the major future renewable resources (see Berndes et al., 2003 for a review of 17 studies of the global bioenergy potential). There is no way to narrowly determine the potential contribution of biomass in a future global industrial society, since it depends on a range of parameters that can vary substantially in the future (Hoogwijk etal., 2003). The aim of this chapter is instead to provide some perspectives and point out a few potentially important issues likely to come into focus in a future of extensive use of biomass for energy and as a renewable feedstock in industry. To begin with, a short review of biomass use in society, including a comparison with other major product and resource flows, followed by an outline of the prospects for non-food crop production and agricultural residue utilization in the future - emphasizing some crucial aspects that so far have received less explicit attention in assessments. After that, the drivers behind increased demand for biomass will be described. The case will be made that the demand for climate-neutral fuels and materials (especially fuels) may lead to a dramatically expanded human biomass use, with implications for biodiversity and nature conservation, and competition for land and other resources. Illustrative outlines of possible consequences are given and discussed. Finally, multifunctional biomass production systems are described. Such systems offer a way to meet the growing biomass demand while at the same time promote environmental protection and sustainable land management, thus providing a possible strategy 
(a)

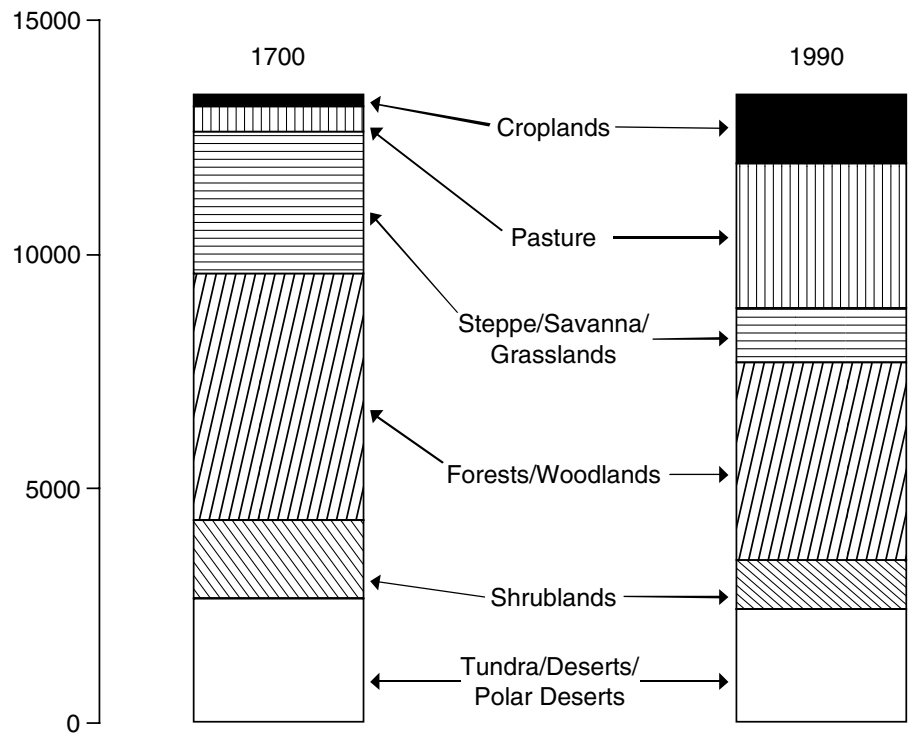

(b) Accumulated $\mathrm{CO}_{2}$ emissions

to the atmosphere $(\mathrm{Pg} \mathrm{C})$

(\%)

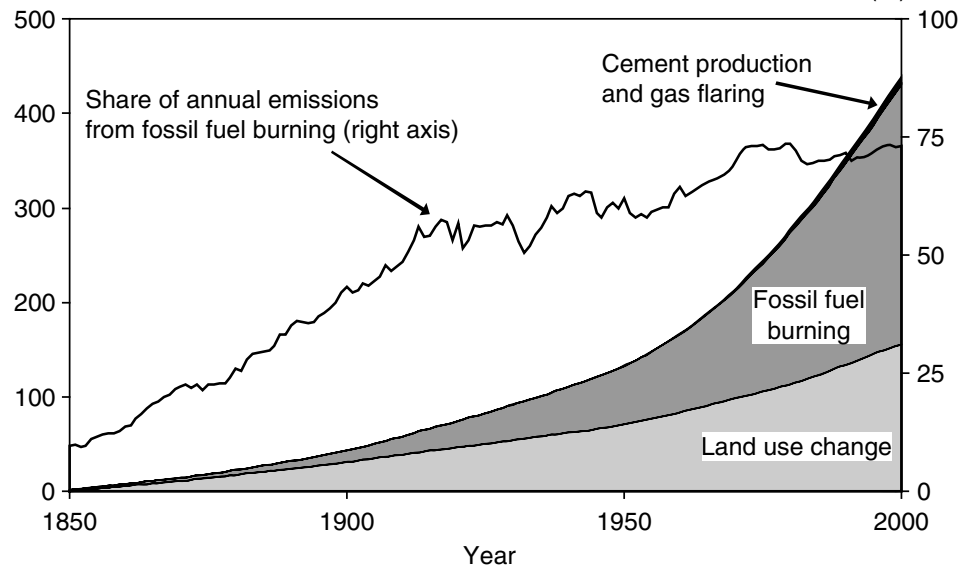

Figure 1.1 Selected indicators of human influence on the Earth system in the past. Figure 1.1a outlines the land transformation during the past 300 years (units: million hectares). Note that this figure does not capture the far-reaching conversion within each given ecosystem type. For example, the conversion of primary natural forests to secondary production forests has resulted in the elimination of a multitude of critical habitats, leading to negative consequences for the state of biodiversity in forest ecosystems. Figure 1.1b presents the anthropogenic $\mathrm{CO}_{2}$ emissions to the atmosphere since 1850 (expressed as carbon in $\mathrm{CO}_{2}$ ). For many decades fossil fuel burning has been the major source of $\mathrm{CO}_{2}$ emissions into the atmosphere, presently contributing close to $75 \%$ of annual emissions. But more than one-third of the accumulated emissions from 1850 to now have been caused by land use change, primarily conversion of forests to agricultural land. In cement production, fossil $\mathrm{CO}_{2}$ is released during the calcination process where calcium carbonate is heated to yield lime. $\mathrm{CO}_{2}$ is also released into the atmosphere when natural gas is 'flared' from petroleum reservoirs Source: Based on Klein Goldewijk (2000) and RIVM (2005). 
to address concerns about climate change and also many other of the most pressing environmental problems of today.

\subsection{Historic and Present Biomass Uses for Food, Energy and Materials in the World}

Figure 1.2 presents a quantification of the biomass production for food, energy and materials. Other major product and resource flows are included for comparison. Figure 1.2 provides some insights in relation to the discussion of the prospects for biomass substituting for non-renewable resources in the future.

From Figure 1.2a, it is evident that the quantitative production of fossil resources is much larger than the biomass production in agriculture and forestry, implying that a farreaching substitution of fossil resources with biomass would require a dramatic increase in the output from agriculture and forestry. Petroleum is to some extent used for the production of plastics and bulk chemicals, some $10-15 \%$ of the coal is used in steel production, and fossil gas (and to some extent also other fossil resources) are used for the production of synthetic fertilizers. But it is the use of fossil fuels in the energy sector that is the main source of society's exploitation of fossil resources. Clearly, the decoupling of societal energy use from biological productivity, that took place more than 100 years ago, has now brought us to energy consumption levels that make it difficult to return to a situation where the global society relies solely on biomass for energy.

The situation is different when looking at materials that are presently primarily produced based on petroleum and fossil gas, e.g., plastics, rubber and various bulk chemicals (Figure 1.2b). This production presently uses $5-10 \%$ of total annual petroleum and gas production and is small compared to the agricultural output: compare, for instance, the present global production of cereals (the major crop type in agriculture) with the plastics production in the world as presented in Figure 1.2b. It is also evident from Figure 1.2b that crop production for non-food/feed uses presently occupies a very small part of agricultural land use: the major part of society's biomass production for material purposes takes place in forestry. However, as will be shown below, agriculture can play a major future role as supplier of renewable feedstocks to industry, substituting non-renewable fossil resources, both by expanding dedicated production of non-food crops and by utilizing organic waste and residues.

The forest sector generates large amounts of biomass residues, both in the forests and at industrial sites such as sawmills and pulp/paper plants. Over the years, the forest industry has improved the wood utilization efficiency by cascading residue flows to energetic or lower value material uses. But the potential for increased residue utilization in forestry is large: increased wood extraction in connection to thinning operations and final logging may yield substantial increases in biomass output. The prospect for increased stemwood extraction by extending and/or intensifying conventional forestry operations is an issue where standpoints diverge, depending on different views regarding environmental, technical, legal and economic restrictions (Nilsson, 1996). The discussion below will focus on the agricultural sector. But several of the issues treated (e.g., the economics of biomass under an ambitious climate policy regime) are relevant also for the forest sector. 
(a) Billion ton

(biomass eq.)

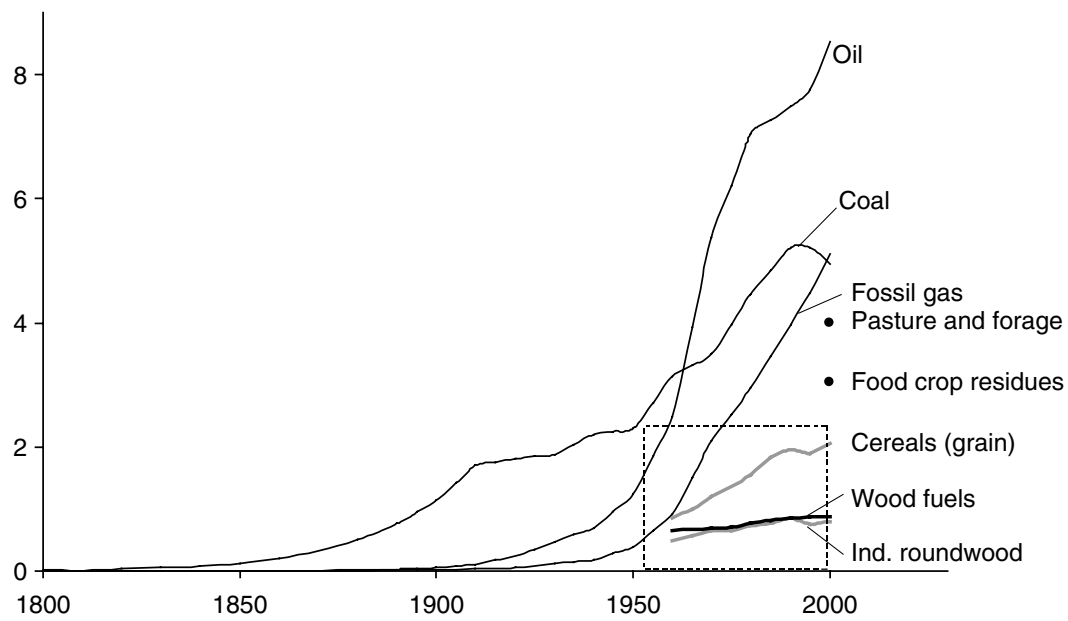

(b) Billion ton

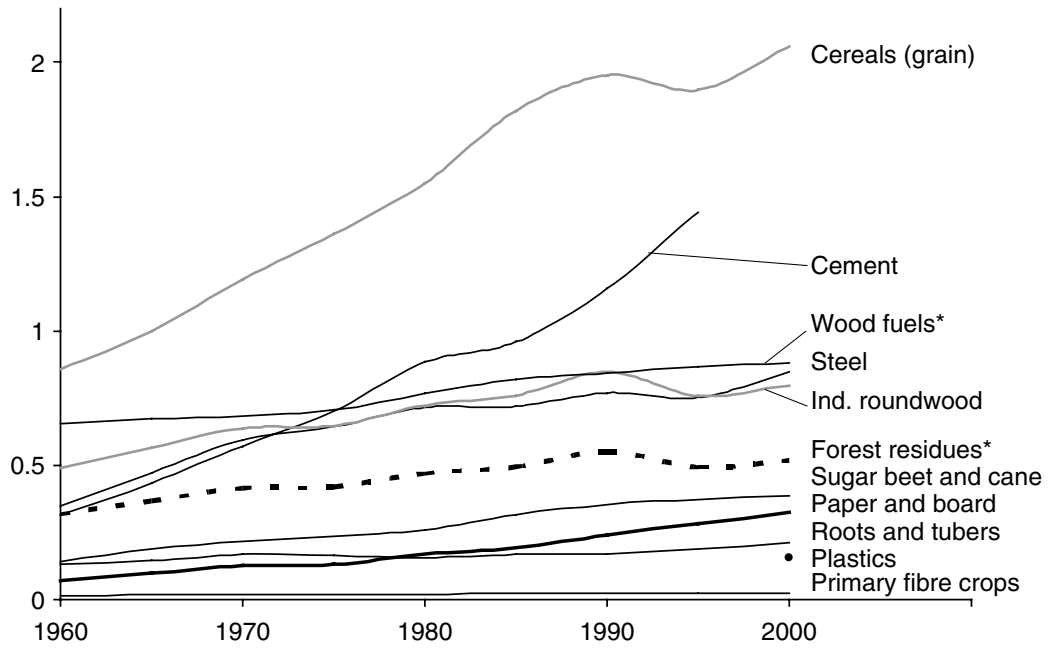

Figure 1.2 Global annual production of major biomass types in agriculture and forestry, and of selected major products and basic resources. The fossil resources are given on a ton biomass equivalent basis (tbe) in order to facilitate a comparison with the different biomass types (conversion based on 1 ton oil equivalent 42 $\mathrm{GJ} ; 1$ the $=18 \mathrm{GJ}$ ). Figure $1.2 \mathrm{~b}$ is a scaled-up segment of Figure 1.2a, including additional products. Only data for the year 2000 are presented for the three categories 'Pasture and forage', 'Food crop residues', and 'Plastics' due to lack of time series data

Note: *'Pasture and forage' refers to the part eaten by grazing animals. 'Forest residues' is indicative of forest biomass availability linked to industrial roundwood production, based on characteristics given in Johansson et al. (1993). 'Wood fuels' (FAO data) does not include all biomass uses for energy. For example, the FAO 'Wood fuels' data for year 2000 corresponds to about $15 \mathrm{EJ}$, while the global biomass use for energy is estimated at about 35-55 EJ per year (Turkenburg, 2000).

Source: Based on Marland et al. (2003), FAOSTAT (2005) and RIVM (2005). 


\subsection{Potential Availability of Agricultural Residues and Land for Non-Food Crop Production}

The total food system appropriation of biological productivity is many times larger than what is finally used by humans. Wirsenius (2003a) estimated the global appropriation of terrestrial plant biomass production by the food system to be some $13 \mathrm{Pg}$ (dry matter) per year in 1992-1994. Of this, about 8\% ended up in food commodities eaten. Animal food systems accounted for roughly two-thirds of the total appropriation of plant biomass, whereas their contribution to the human diet was about 13\% (gross energy basis). The ruminant meat systems were found to have a far greater influence than any other subsystem on the food system's biomass metabolism, primarily because of the lower feed-conversion efficiency of those systems. Based on this notion, one suspects that: (i) there are potentially major industrial (and energy) feedstocks to be found in the large pool of appropriated biomass not ending up as food; and (ii) there is scope for mitigating the long-term land use demand in the food sector by increases in efficiency (including dietary preferences). Both options are attractive in that they offer opportunities for increasing the use of biomass in industry, and in the energy sector, without imposing further conversion of natural land to agricultural uses.

In order to gain a better understanding of these opportunities, a mass and energy balanced model of the global food system was used to assess how the global biomass potential is influenced by different development paths in the food and agriculture system (Wirsenius, 2003a, 2003b; Wirsenius et al., 2004). The starting point for the analysis was the recent projections of global agriculture up to 2030 made by the Food and Agriculture Organization of the United Nations (FAO) (Bruinsma, 2003). In addition to the 'Reference' scenario, depicting the FAO projection, three explorative scenarios were developed: 'Increased livestock productivity' (IP); 'Ruminant meat substitution' (RS); and 'More vegetarian food and less food wastage' (VE).

The results from the scenarios indicate that if the projections made by the FAO come true, the prospects for non-food crop production will be less favourable. In the scenario depicting the FAO projection, it is estimated that total agricultural land area globally will expand from current 5.1 billion hectares to approximately 5.4 billion hectares in 2030 (Figure 1.3). This means that a major expansion of non-food crops would require even further conversion of natural to cultivated land. However, as shown in scenario IP, if livestock productivity increases faster than projected by the FAO, global land requirement for food may actually decrease to 2030. Furthermore, as shown in scenario RS and VE, if the higher livestock productivity is combined with changes in diets (a $20 \%$ substitution of ruminant meat with pig/poultry meat) and reduced food wastage, global agricultural land demand may decrease to 4.2-4.4 billion hectares (Figure 1.3). If the surplus agricultural land was targeted for non-food crop cultivation, a considerable amount of biomass could be produced without claiming land beyond what has already been appropriated.

In the IP, RS and VE scenarios, also the amount of food-system residues and by-products available for non-food purposes will be higher than in the FAO projection (Figure 1.4), mainly due to a lower use of crop residues as feed in those scenarios. In, e.g., the European regions, agricultural land demand decreases also in the Reference scenario, due to decreasing population (-8\% from 1998 to 2030) and continuing rises in crop and livestock productivity. This is in contrast with the developing regions, where population growth 
Million hectare

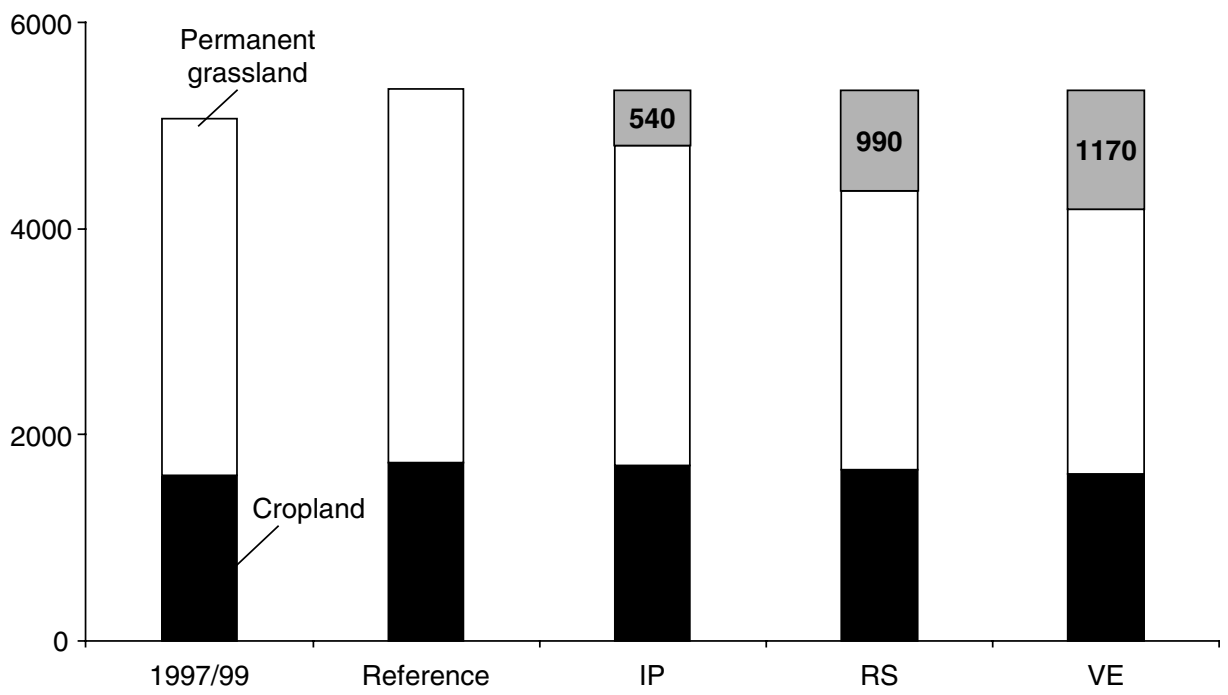

Figure 1.3 Present and estimated future global extent of agricultural land in the scenarios. The Reference scenario depicts the $F A O$ projection. Alternative scenarios: $I P=$ increased livestock productivity; $R S=$ ruminant meat substitution; and VE=more vegetarian food and less food wastage. The shaded topmost part of each alternative scenario column indicates the difference in land requirements for food production between the Reference scenario and the alternative scenario.

Source: Based on Wirsenius et al. (2004). Reproduced by permission of ETA-Florence/WIP-Munich.

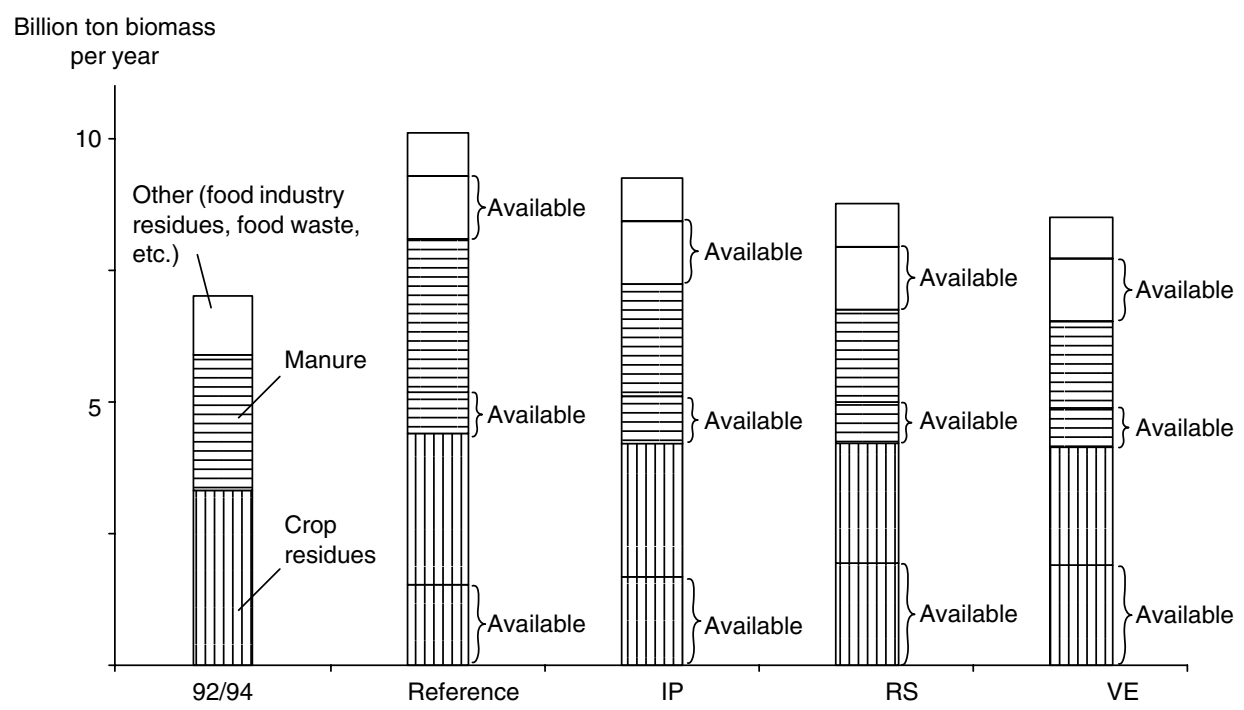

Figure 1.4 Estimated production of by-products and residues in the global food system. The amounts possibly available for use as feedstock for industry or for energy 2030 in the scenarios are indicated Source: Based on Wirsenius et al. (2004). Reproduced by permission of ETA-Florence/WIP-Munich. 
and increasing food consumption per capita add to rising land demand, as in, e.g., Latin America.

The above scenario exercise indicates that biomass from surplus cropland and from food sector residues may indeed play a large role as a renewable feedstock and help reduce the present dependence on non-renewable energy and materials. The scope for establishment of bioenergy plantations on surplus cropland may be considerable: if the food sector development follows a path similar to that in the RS/VE scenarios, a global biomass supply from plantations of the order of 3-6 billion ton per year does not seem to be impossible with regard to the land requirements of food production. Also the potential supply of biomass residues from the food system is impressive, being of the order of 3-4 billion ton per year. However, it is also clear that food sector development - and especially dietary preferences and the development of animal production efficiency - strongly influence the potential.

It is not axiomatic that the use of biomass resources is environmentally superior to the use of non-renewable resources. Both the dedicated production of feedstock crops and the collection of residues can lead to undesired environmental impacts and it is crucial that practices are found that ensure that reduction of one environmental impact does not increase another. However, if guided in sound directions, a growing biomass demand may be instrumental in promoting sustainable land management. This will be discussed further in a later section, where it will be described how biomass plantations can be located, designed and managed so as to generate environmental benefits in addition to those associated with the substitution of nonrenewable fuels or industrial feedstocks.

\subsection{Drivers Behind Increasing Demand for Biomass for Energy and Materials}

There are several factors behind today's interest in biomass as industrial feedstock and for the production of fuels and electricity. One early driver was the need to reduce food crop surpluses and find productive use of agricultural land in industrialized countries experiencing overproduction of food. Also, concern about high energy prices connected to the 1970s' oil crisis spurred an interest in the use of domestic energy sources to reduce dependence on foreign oil. At the same time, the insight that the industrial practices and consumption patterns of the western world seriously damage the environment stimulated a search for recyclable, biodegradable and less toxic materials. In this context, biomass was seen as a potentially important domestic, renewable resource, with the potential to meet the demand for more environmentally benign feedstocks in industry as well as for the production of fuels and electricity.

However, today's interest in biomass as a raw material for industry is not without precedents. For example, the farm chemurgy movement in the United States promoted the use of farm crops as industrial feedstocks more than half a century ago, partly due to similar concerns (Finlay, 2004). The difference is that today technology development has put us in a situation where industry can produce biofuels and bioproducts with a quality that satisfy a high consumer demand. Similar to when humans learned to use fossil feedstocks to create advanced synthetic materials with unique properties, the conversion of biomass to fuels and bioproducts continuously develops into increasingly sophisticated processes. 
Modern biotechnology, material science, agricultural and process engineering today allow for a number of biobased products such as biodegradable plastics, oleochemicals, biocomposites, bulk chemicals, and biofuels.

The use of bioenergy for the production of heat and electricity has successfully increased in countries like Finland and Sweden. As the utilization has increased, the techniques and technologies to collect, transform and transport biomass have improved so as to reduce costs. Due to such developments the potential bioenergy resources have appeared to increase and there are optimistic scenarios suggesting that biofuels could also be used to replace significant parts of the fossil fuels used for transport. Stimulated by directives and regulations, first-generation liquid biofuels, such as ethanol and biodiesel based on traditional starch, sugar and oil crops, penetrate markets in, e.g., the European Union. Second-generation liquid biofuels, such as Fischer Tropsch fuels, Dimethyl Ether, lignocellulose-based ethanol and hydrogen based on gasification of biomass, are envisioned to become increasingly competitive to their fossil alternatives as technologies develop and allow production based on more abundant and potentially much cheaper lignocellulosic feedstocks.

Thus, technology development in processing biomass to fuels and materials can be expected to make possible a wide range of options for the substitution of non-renewable resources. This includes the continuation, and expansion, of 'traditional' practices such as the use of vegetable oils for lubricants and coatings, and of wood for buildings, and also new uses of established crops, such as natural fibres replacing glass fibre in composites. But it is the substitution of non-renewable (fossil) resources in the energy sector that poses the greatest challenge from the perspective of renewable resources availability (Figure 1.2). Environmental scarcities (i.e., limitations of the capacity of the ecosphere to assimilate societal emissions to air and water) rather than fossil resources scarcity determine the required extent and rate of this substitution, and the concern about humaninduced climate change is possibly the most important driver for change.

Radical change of the global energy system is required if we are to reach stringent climate targets. This is a daunting challenge. For example, governments, several scientists, and environmental organizations have argued in favour of an upper limit on the increase in the global annual average surface temperature set at or around $2{ }^{\circ} \mathrm{C}$ above pre-industrial temperature levels. Such a target may require that atmospheric $\mathrm{CO}_{2}$ concentrations are kept below 400 ppm (Azar and Rodhe, 1997), implying that total global $\mathrm{CO}_{2}$ emissions by the year 2100 would have to drop to around 2 billion ton carbon (C) per year. Assuming a global population of 10 billion people in 2100, global average per capita emissions would then have to drop to about 0.2 ton $C$ per capita and year by 2100 . This is below the level that prevails in India today. In fact, even if a less ambitions climate target is chosen, the total global emissions would eventually have to drop to levels below 2 billion ton C per year also for these higher concentration targets (Houghton et al., 2001).

At the same time, global energy consumption is expected to more than double during the twenty-first century. This means that the requirements of $\mathrm{CO}_{2}$ neutral energy may have to grow to levels several times the present global total fossil fuel use, if we are to avoid venturing into a future with a doubled, tripled or even quadrupled pre-industrial atmospheric $\mathrm{CO}_{2}$ level.

Surveys of possible future energy sources come up with several candidates capable of supplying large amounts of $\mathrm{CO}_{2}$-neutral energy, including solar and wind energy, bioenergy, 
nuclear fission and fusion, and fossil fuels with carbon capture and sequestration (Hoffert et al., 2002). But bioenergy ranks as one of few technological options capable of tackling climate change already today: being a low cost renewable fuel already competitive on some markets, and near penetration into new applications as policies, markets and related technologies develop. Advanced technologies, such as nuclear fusion, may eventually satisfy safety requirements and offer abundant energy supplies, but a prudent strategy for tackling the challenge of climate change cannot rely on those to aid $\mathrm{CO}_{2}$ stabilization during the twenty-first century. Rather than awaiting the prospective (30-50 years ahead) realization of potential silver bullet solutions, society, people and companies will have to turn to what is available closer in time - regardless of whether the estimated ultimate long-term contribution of these options correspond to 30 or $300 \%$ of the present world energy use.

Since the potential biomass supply is low compared to the required levels of $\mathrm{CO}_{2}$ neutral energy - almost regardless of whether one is optimistic or pessimistic about the potential biomass supply - more costly $\mathrm{CO}_{2}$-neutral energy sources will have to enter if low $\mathrm{CO}_{2}$ targets should be reached. When such energy technologies are in place, they will most likely cost substantially more than bioenergy, and therefore bioenergy will remain very competitive even in the scenario where advanced energy technologies have come to dominate the global energy supply. The more costly carbon-free energy sources can be expected to set the energy price at a level that would lead to higher profits for the bioenergy sector. With these higher profits, farmers would get stronger economic incentives to turn to bioenergy unless food prices rise to the point where profits are as large as in the energy sector. Thus, land and food prices are likely to be pushed upwards. The implications of such a development are discussed further in the next section.

\subsection{Land Use Competition}

The economics of land use will be different in a world where carbon and $\mathrm{CO}_{2}$ have a price. The value of the carbon flows that are induced by different land use practices may become similar to the value of the primary product output from the very same practices. The cost of inputs such as nitrogen fertilizers and diesel will increase, but - potentially much more important - the food and forestry sectors will also have to face increasing competition from the energy sector. Food and bioenergy interactions and competition for scarce land and biomass resources have been the subject of several studies (Azar and Berndes, 1999; Azar and Larson, 2000; McCarl and Schneider, 2001; Johansson and Azar, 2003; Sands and Leimbach, 2003). Forest sector concerns about increasing energy sector demand for biomass are expressed in, e.g., Dielen et al. (2000) and policies stimulating this development are even argued to induce developments towards less eco-efficient use of forest wood (Van Riet, 2003).

Azar (2005) presents detailed modelling as well as some illustrative calculations of the willingness to pay for biomass in a world striving for low emissions. Based on a survey of future energy technology costs, and that the marginal energy price will be set by advanced technologies such as solar hydrogen, it is shown that farmers could sell biomass for energy at a price that is four to five times the estimated production cost. If such a situation were to materialize, it is estimated that land values might increase by an order of magnitude, and food prices might increase by a factor of two to five. 
Figure 1.5 illustrates the same prospect, but for the case of electricity generation under a carbon tax/permit price regime. The fossil options are cheapest at low carbon tax rates, but the economic performance changes with increasing tax rates and at about 40 and $110 € /$ ton $\mathrm{C}$ tax rate, biomass electricity becomes cheaper than coal and fossil gas based electricity respectively. Capture and sequestration of $\mathrm{CO}_{2}$ from coal combustion (carbon $\mathrm{C} \& \mathrm{~S}$ ) becomes competitive with conventional coal technologies at around $75 € /$ ton $\mathrm{C}$, and the same happens for fossil gas at about $135 € /$ ton C.

Figure 1.5 also illustrates the interesting cost development for biomass-based electricity generation combined with carbon C\&S: the cost will drop if the plant owner gets paid for capture and sequestration of the carbon. At a $225 € /$ ton $C$ carbon tax, biomass-based electricity can be produced at no cost since the revenues from the carbon C\&S cover the costs of electricity generation. A plant owner running a biomass-fired power plant would obviously be willing to pay much for the biomass in a situation with such carbon taxes/ permit prices. For comparison, the Swedish carbon tax on the transportation sector and on household and district heating is presently about $290 € /$ ton C.

The socio-economic consequences of higher land values and higher food prices, are complex and there are different views about how a large biomass demand would influence development in agriculture. On the one hand, human demand for conquering more bioproductive lands might lead to the conversion of biodiversity rich ecosystems into monocultural biomass plantations, and poor people might be evicted from their lands. On the other hand, higher land values will stimulate increased land conservation efforts on agricultural land and it might generate income for the rural poor.

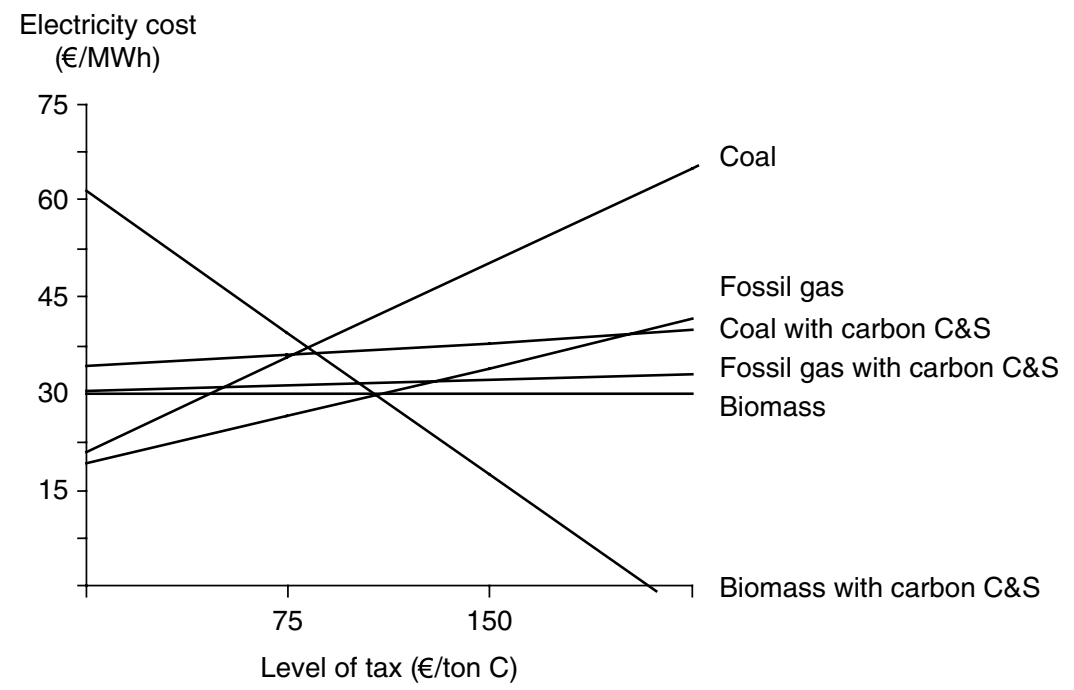

Figure 1.5 Electricity generation cost for different feedstock and technology options under a carbon tax regime. The term 'carbon $\mathrm{C} \& S^{\prime}$ indicates that the $\mathrm{CO}_{2}$ arising from fuel combustion is captured and sequestered in the ocean or in underground geologic repositories. Addition of carbon C\&S leads to increased technology costs but much less sensitivity of electricity cost to carbon taxes. However, the electricity cost increases slowly with rising carbon taxes since not all $\mathrm{CO}_{2}$ is captured in the $\mathrm{C} \& S$ operations

Source: Based on Azar et al. (2005), using the exchange rate 1 USD $=0.75 €$. Reproduced from Climatic Change (in press) 2006, Azar et al. with kind permission from Springer Science and Business Media. 
Biomass plantations can be established on degraded or otherwise marginal land, where production of food crops is not economically viable. It has been suggested that by targeting such land, farmers could restore soil organic matter and nutrient content, stabilize erosion and improve moisture conditions. In this way an increasing biomass demand could become instrumental in the reclamation of land that has been degraded from earlier over-exploitation and improper management (Hall etal., 1993). However, studies indicate that biomass production on marginal/degraded land may not be the automatic outcome of increasing biomass demand (Johansson and Azar, 2003; Azar and Larson, 2000). If the allocation of land is done by profit-maximizing farmers and forestry companies, prime cropland may be targeted if the higher yields on the better soils outweigh the increased land costs. Biomass plantations may eventually be pushed to marginal/degraded land due to increasing land costs following increased competition for prime cropland, but this competition will likely also be reflected in increasing food commodity prices.

In industrialized countries, this may be less of a problem since food commodity prices only constitute a minor share of retail food prices, and the share of personal consumption expenditure spent on food is moderate. However, in developing countries where food often accounts for a very substantial part of total household consumption, the situation is different. An increase in the prices of staple food crops might cause an increased number of, or a worsened situation for, people chronically hungry and undernourished. Thus, the balance of distributional impacts is difficult to assess. Still, the risk that more people will be affected by hunger must not be disregarded. In a scenario with unequal economic development in the world, a large bioenergy demand with strong paying capacity in industrialized countries may impact food security and food availability in developing countries, creating a moral dilemma in the development of bioenergy strategies.

These potential impacts should not be taken as arguments against policies aimed at reducing $\mathrm{CO}_{2}$ emissions. Rather, they imply that $\mathrm{CO}_{2}$ abatement policies cannot be assessed in the absence of distributional considerations and are a clear signal of the importance of global and national efforts to advance development and reduce poverty in the world, especially in developing countries. Synergies and joint action with other multilateral environmental conventions and agreements should be sought, in order to ensure that $\mathrm{CO}_{2}$ abatement policies do not aggravate the situation in relation to, e.g., food security, water resources and biodiversity.

In the concluding section, one possible strategy for addressing the concerns about climate change and also many other of today's most pressing environmental problems, is briefly presented.

\subsection{Multifunctional Biomass Production Systems}

Research carried out in Sweden and elsewhere reveals that the environmental benefits from a large-scale expansion of properly located, designed and managed biomass plantations could be substantial, as the negative environmental impacts from current agriculture practices and also municipal waste treatment could be significantly reduced (Berndes et al., 2004; Berndes and Börjesson, 2004; Börjesson and Berndes, 2005; Lewandowski etal., 2004). 
Multifunctional biomass production systems can be defined as systems that, besides producing biomass for substitution of fossil resources, also provide additional environmental services. The potential for multifunctional biomass production systems based on Salix (Multifunctional Salix Plantations, MSPs) in Sweden has been assessed and the results are very encouraging: about 15000 hectares are used for Salix production in Sweden today. An estimated 50000 hectares could be dedicated to MSP systems providing environmental services having an estimated economic value exceeding the total cost of Salix production. On more than 100000 hectares, the biomass could be produced in MSPs providing environmental services having an estimated value above, or roughly equal to, half the biomass production cost (Figure 1.6).

Thus, given that additional revenues - corresponding to the economic value of the provided environmental services - can be linked to the MSP systems, the economic performance of such biomass production can improve dramatically. Biomass supply from MSPs could bring substantial improvements in the biomass supply cost and also in other aspects of competitiveness against conventional resources. Establishment and expansion of such plantation systems would also induce development and cost reductions along the whole biomass supply chain. Thus, MSPs could become prime movers and pave the way for an expansion of low cost perennial crop production for the supply of biomass as industrial feedstock and for the production of fuels and electricity.

The production and use of biomass from multifunctional biomass production systems would not only contribute to the development towards more sustainable energy and

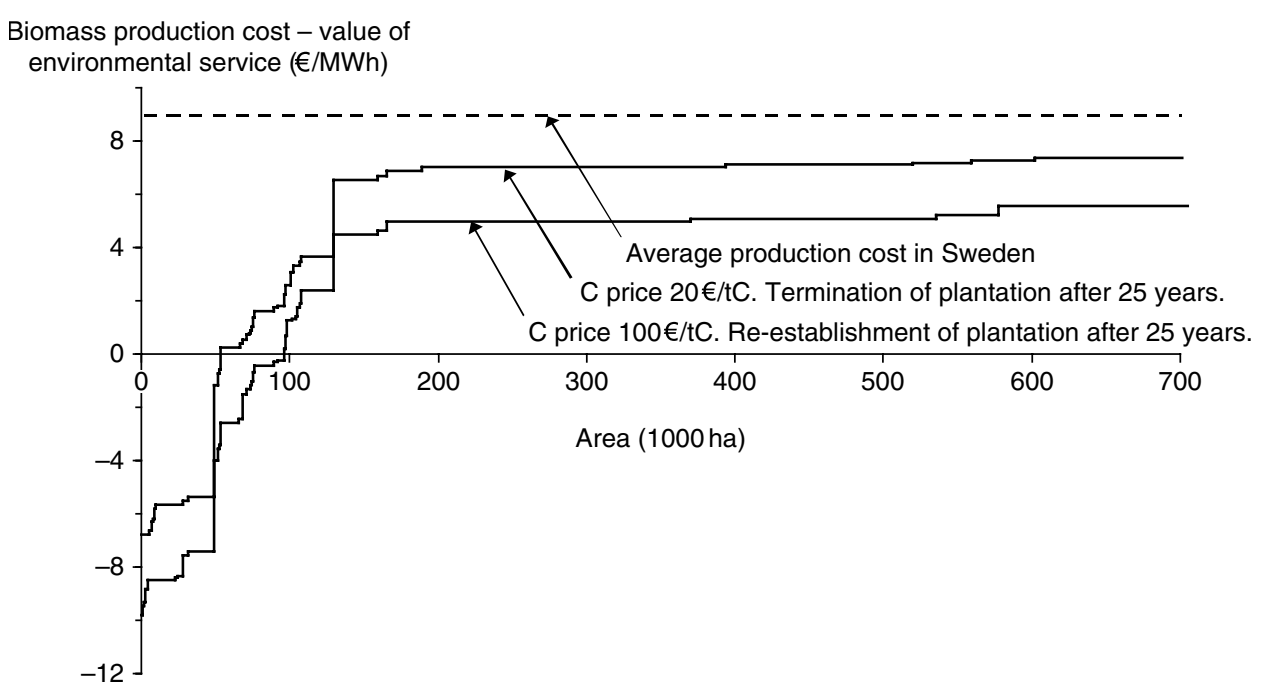

Figure 1.6 The practical potential for multifunctional bioenergy systems in Sweden, and an illustration of the estimated value of the additional environmental services provided, as they relate to the cost of Salix production. Assessed environmental services include: reduction of nutrient leaching and soil erosion; cadmium removal from agricultural land; increased nutrient recirculation and improved treatment efficiency of nutrient-rich drainage water and pre-treated municipal wastewater and sludge; and provision of habitats and contribution to enhanced biodiversity and game potential

Source: Based on Berndes and Börjesson (2004). Reproduced by permission of ETA-Florence/WIP-Munich. 
industrial production, but also to development towards a more sustainable agriculture and to increased recirculation and efficiency in societal use of essential resources such as phosphorus and other nutrients. This way, multifunctional biomass production systems may become a valuable tool also for meeting additional great challenges such as getting the world's water cleaner and preserving the long-term quality of agricultural soils.

\subsection{Summary}

The use of biomass as a renewable feedstock in industry, and for the production of fuels, heat and electricity, can help reduce our dependence on non-renewable energy and materials. The question is not whether it is technically possible to supply several billion tons of biomass for energy and industry every year, but rather whether it can be done acceptably from a social and environmental point of view. A key question will be how to make sure that a large-scale expansion of biomass use for energy complies with other urgent environmental objectives, such as reduced erosion and land degradation, reduced eutrophication, good quality groundwater, a rich agricultural landscape, nature conservation and the protection of global biodiversity. These are prerequisites for bioenergy and biomaterials to be regarded as attractive options for the future.

If guided in sound directions, the growing biomass demand can be instrumental in promoting sustainable land management. The case of multifunctional Salix plantations in Sweden points the way for an expanded supply of biomass that should be systematically explored in both industrialized and developing countries. Besides estimating the potential extent and economic value of the environmental services that can be provided, a key issue will be to identify suitable mechanisms to put a premium on the environmental services provided. In some cases, actors can be identified that are willing to pay for a specific environmental service. In other situations, information campaigns and innovative government measures that credit the biomass producer may be required in order to stimulate the establishment of multifunctional biomass production systems. A challenge when implementing such measures lies in the harmonization of the different policies in the energy, environmental and agricultural fields.

\section{Acknowledgements}

This chapter builds further on earlier collaboration with Christian Azar and Stefan Wirsenius at Chalmers and Pål Börjesson at Lund University.

\section{References}

Azar, C. (2005) Emerging scarcities: Bioenergy-food competition in a carbon constrained world, in Simpson, D., Toman, M. and Ayres, R. (eds) Scarcity and Growth in the New Millennium, Resources for the Future Inc./Johns Hopkins University Press, Baltimore, MD.

Azar, C. and Berndes, G. (1999) The implication of $\mathrm{CO}_{2}$-abatement policies on food prices, in Dragun, A. and Tisdell, C. (eds) Sustainable Agriculture and Environment: Globalisation and Trade Liberalisation Impacts, Edward Elgar: Cheltenham. 
Azar, C. and Larson, E. D. (2000) Bioenergy and land-use competition in Northeast Brazil, Energy for Sustainable Development, 4, 64-71.

Azar, C., Lindgren, K., Larson, E. D. and Möllersten, K. (2005) Carbon capture and storage from fossil fuels and biomass: Costs and potential role in stabilizing the atmosphere, Climatic Change, forthcoming.

Azar, C. and Rodhe, H. (1997) Targets for stabilization of atmospheric $\mathrm{CO}_{2}$, Science, 276, 1818-1819.

Berndes, G. and Börjesson, P. (2004) Low cost biomass produced in multifunctional plantations the case of willow production in Sweden, in 2nd World Conference on Biomass for Energy, Industry and Climate Protection, Rome, Italy, 10-14 May, pp. 289-292.

Berndes, G., Fredriksson, F. and Börjesson, P. (2004) Cadmium accumulation and Salix based phytoextraction on arable land in Sweden, Agriculture, Ecosystems and Environment, 103, 207-223.

Berndes, G., Hoogwijk, M. and van den Broek, R. (2003) The contribution of biomass in the future global energy supply: a review of 17 studies, Biomass and Bioenergy, 25, 1-28.

Börjesson, P. and Berndes, G. (2005) The prospects for willow plantations for wastewater treatment in Sweden, Biomass and Bioenergy, in Press.

Bruinsma, J. (ed.) (2003) World Agriculture: Towards 2015/2030. An FAO Perspective, Earthscan Publications Ltd, London.

Dielen, L. J. M., Guegan, S., Lacour, P.-A., Mäki, P. K., Stolp, J. A. N. and Rytkönen, A. (2000) EU Energy Policy Impacts on the Forest-Based Industry, Part 1, Modelling Analysis of the Influence of the EC White Paper on Renewable Energy Sources on the Wood Supply to the European Forest-Based Industries. Stichting Probos, Wageningen, The Netherlands.

FAOSTAT, Statistical database of the FAO, Food and Agriculture Organization of the United Nations, Rome, Italy. Available at: www.faostat.fao.org/Accessed January 2005.

Finlay, M. R. (2004) Old efforts at new uses: a brief history of Chemurgy and the American search for biobased materials, Journal of Industrial Ecology, 7, 33-46.

Groombridge, B. and Jenkins, M. D. (2002) World Atlas of Biodiversity: Earth's Living Resources in the 21st Century, University of California Press, Berkeley, CA.

Hall, D. O., Rosillo-Calle, F., Williams, R. H. and Woods, J. (1993) Biomass for energy: supply prospects, in Johansson, T. B., Kelly, H., Reddy, A. K. N. and Williams, R. H. (eds), Renewable Energy: Sources for Fuels and Electricity, Island Press, Washington, DC, pp. 593-651.

Hoffert, M. I., Caldeira, K., Benford, G., Criswell, D. R., Green, C., Herzog, H., Jain, A. K., Kheshgi, H. S., Lackner, K. S., Lewis, J. S., Lightfoot, H. D., Manheimer, W., Mankins, J. C., Mauel, M. E., Perkins, L. J., Schlesinger, M. E., Volk, T. and Wigley, T. M. L. (2002) Advanced technology paths to global climate stability: energy for a greenhouse planet, Science, 298, 981-987.

Hoogwijk, M., Faaij, A., van den Broek, R., Berndes, G., Gielen, D. and Turkenburg, W. (2003) Exploration of the ranges of the global potential of biomass for energy, Biomass and Bioenergy, 25, 119-133.

Houghton, J. T., Ding, Y., Griggs, D. J., Noguer, M., van der Linden, P. J. and Xiaosu, D. (eds) (2001) Climate Change 2001: The Scientific Basis. Contribution of Working Group I to the Third Assessment Report of the Intergovernmental Panel on Climate Change, Cambridge University Press, Cambridge.

Johansson, D. and Azar, C. (2003) Analysis of land competition between food and bioenergy, World Resources Review, 15, 165-175.

Johansson, T. B., Kelly, H., Reddy, A. K. N., Williams, R. H. and Burnham, L. (eds) (1993) Renewable Energy: Sources for Fuels and Electricity, Island Press, Washington, DC.

Klein Goldewijk, K. (2000) Estimating global land use change over the past 300 years: the HYDE database, Global Biogeochemical Cycles, 15, 417-434.

Lewandowski, I., Londo, M., Schmidt, U. and Faaij, A. (2004) Biomass production in multiple land use systems: categorization of feasible land use functions and their quantification by the example of phytoremediation, paper at World Conference and Technology Exhibition on Biomass for Energy, Industry and Climate Protection, Rome, Italy.

Marland, G., Boden, T. A. and Andres, R. J. (2003) Global, regional, and national $\mathrm{CO}_{2}$ emissions, in Trends: A Compendium of Data on Global Change, Carbon Dioxide Information Analysis Center, Oak Ridge National Laboratory, US Department of Energy, Oak Ridge, TN, USA.

McCarl, B. A. and Schneider, U. A. (2001) Greenhouse gas mitigation in US agriculture and forestry, Science, 294, 2481-2482.

Nilsson, S. (1996) Do We Have Enough Forests? International Union of Forestry Research Organisations (IUFRO), Vienna. 
Oldeman, L. R., Hakkeling, R. T. A. and Sombroek, W. G. (1991) World Map of the Status of Human-Induced Soil Degradation: An Explanatory Note, October 1991, 2nd revised edition. International Soil Reference and Information Centre (ISRIC)/United Nations Environment Programme (UNEP), Wageningen, The Netherlands.

Ponting, C. (1992) A Green History of the World: The Environment and the Collapse of Great Civilizations, St. Martin's Press, New York.

RIVM, History Database of the Global Environment - HYDE, National Institute of Public Health and the Environment, Bilthoven, the Netherlands. Available at: http://arch.rivm.nl/env/int/hyde/. Accessed January 2005.

Sands, R. D. and Leimbach, M. (2003) Modeling agriculture and land use in an integrated assessment framework, Climatic Change, 56, 185-210.

Smil, V. (2001) Enriching the Earth: Fritz Haber, Carl Bosch, and the Transformation of World Food Production, MIT Press, Cambridge, MA.

Turkenburg, W. C. (2000) Renewable energy technologies, in Goldemberg, J. (ed.), World Energy Assessment UNDP/UN-DESA/WEC, New York.

Turner II, B. L., Clark, W. C., Kates, R. W., Richards, J. F., Mathews, J. T. and Meyer, W. B. (eds) (1990) The Earth as Transformed by Human Action: Global and Regional Changes in the Biosphere over the Past 300 Years, Cambridge University Press, Cambridge.

Van Riet, C. (2003) Impacts of the EU energy policy on the woodworking industries: the sound use of wood from an industries perspective, in Strategies for the Sound Use of Wood, Poiana Brasov, Romania.

Wirsenius, S. (2003a) The biomass metabolism of the food system: a model-based survey of the global and regional turnover of food biomass, Journal of Industrial Ecology, 7, 47-80.

Wirsenius, S. (2003b) Efficiencies and biomass appropriation of food commodities on global and regional levels, Agricultural Systems, 77, 219-255.

Wirsenius, S., Azar, C. and Berndes, G. (2004) Global bioenergy potentials: a new approach using a model-based assessment of biomass flows and land demand in the food and agriculture sector 2030, in 2nd World Conference on Biomass for Energy, Industry and Climate Protection, Rome, Italy, pp. 471-474. 